\title{
Um relato de experiência no ensino de funções quadráticas com a utilização do software Geogebra
}

\section{An experience report in teaching quadratic functions with the use of Geogebra software}

\author{
José Robyson Aggio Molinari \\ Universidade Estadual do Centro-Oeste (UNICENTRO), Irati, PR, Brasil \\ http://orcid.org/0000-0002-1368-8719, irmolinari@unicentro.br \\ Lidiane Aparecida dos Santos \\ Universidade Estadual do Centro-Oeste (UNICENTRO), Irati, PR, Brasil \\ http://orcid.org/0000-0003-3365-7087, llidissantos@gmail.com \\ Franciéle Maria de Souza Retslaff \\ Universidade Estadual do Centro-Oeste (UNICENTRO), Irati, PR, Brasil \\ http://orcid.org/0000-0002-7202-1738, francieleretslaff@yahoo.com.br
}

Informações do Artigo

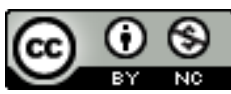

Histórico do Artigo

Submissão: 15 de outubro de 2018

Aceite: 28 de dezembro de 2018.

\section{Palavras-chave}

Geogebra

Funções Quadráticas

Investigação

\section{Resumo}

Este trabalho teve como objetivo investigar a utilização do software Geogebra no ensino de funções quadráticas, em uma turma do $9^{\circ}$ ano do Ensino Fundamental de uma escola pública, analisando como as mídias tecnológicas e a investigação podem ser metodologias muito eficazes no desenvolvimento do aluno em relação à aprendizagem dos conteúdos matemáticos. Foi introduzido o conteúdo de funções quadráticas e algumas atividades referentes à construção de gráficos, que foram realizadas no caderno. Posteriormente, foi apresentado aos alunos o software Geogebra. Conclui-se que a eficácia da utilização de uma metodologia diferenciada no ensino, como o uso do software, de maneira organizada e em conjunto com o conteúdo base dos alunos, torna-se uma ferramenta importante no entendimento dos conteúdos, despertando maior interesse por eles.

\section{Abstract}

Keywords

Geogebra

Quadratic Functions

Investigation
This work aimed to investigate the use of Geogebra software in the teaching of quadratic functions in a class of the 9th grade of a public school, analyzing how technological media and research can be very effective methodologies in student development in relation to the learning of mathematical contents. It was introduced the content of quadratic functions and some activities related to the construction of graphs, which were carried out in the notebook. Later, the students were introduced to Geogebra software. It is concluded that the effectiveness of using a differentiated methodology in teaching, such as the use of software, in an organized manner and in conjunction with the basic content of the students becomes an important tool in understanding the content and arousing greater interest in it.

\section{Introdução}

A tecnologia é um dos recursos disponíveis para o ensino da Matemática, sendo um convite tentador utilizá-la como um recurso no ensino-aprendizagem, em que a maneira tradicional, algumas vezes, enfrenta diversas dificuldades, como a falta de interesse e motivação do educando, 
pelo qual, além do professor ter de apresentar os conteúdos que devem ser tratados em aula, também deve despertar no aluno o desejo do conhecimento e que este conhecimento seja realmente proveitoso.

Com isso, nas últimas décadas, surgiram novas maneiras de pensar e novos métodos em relação à forma de ensinar Matemática, como as tendências metodológicas: Etnomatemática, Modelagem Matemática, Mídias Tecnológicas, História da Matemática, Investigação Matemática e Resolução de Problemas, apresentadas pela Diretrizes Curriculares do Estado do Paraná (SEED, 2008), que permitem a abertura de novas possibilidades para o aprendizado, fazendo com que o aluno tenha a oportunidade de participar ativamente na construção do conhecimento e tenha garantida uma aprendizagem mais significativa e duradoura.

Esses novos métodos de ensino buscam apresentar o conhecimento matemático de forma contextualizada, para que haja a percepção das aplicações nos conteúdos ensinados, tornando assim o ensino da Matemática mais prático, pois facilita a compreensão dos conceitos. Segundo as Diretrizes Curriculares do Estado do Paraná (SEED, 2008, p. 63), os conteúdos propostos devem ser abordados por meio de tendências metodológicas da Educação Matemática que fundamentam a prática docente. Dentre essas tendências, destaca-se a Investigação Matemática e as Mídias Tecnológicas, que surgiram para aumentar a eficácia nos processos de ensino e de aprendizagem e são apontadas como metodologias dinâmicas. Este despertar ocorre especialmente pelo fato de que as tecnologias fazem parte da realidade do aluno e, além disso, faz com que a curiosidade, por se tratar de algo novo, diferente, auxilie nas descobertas feitas pelo próprio aluno enquanto busca respostas por meio dessas metodologias, como apontam Ponte et al. (2006, p. 9):

[...] em contextos de ensino e aprendizagem, investigar não significa necessariamente lidar com problemas muito sofisticados na fronteira do conhecimento. Significa, tão só, que formulamos questões que nos interessam, para as quais não temos resposta pronta, e procuramos essa resposta de modo tanto quanto possível fundamentado e rigoroso.

De acordo com Fernandes et al. (2017), todo o profissional da educação (professor), deve estar em constante aprimoramento e reciclagem dos conteúdos e assuntos pertinentes à sua área de ensino.

Logo, por meio dos softwares, o professor tem a oportunidade de transformar o ambiente de ensino e abordar os conteúdos de uma maneira diferenciada, visando uma aprendizagem consistente e atraente, já que, nesse contexto, os alunos visualizam o desenvolvimento das teorias e não apenas seguem um modelo. De acordo com Lima (2006, p. 36),

[...] ao considerar as possibilidades de ensino com o computador, o que pretendo destacar é a dinamicidade desse instrumento que pode ser utilizado para que os alunos trabalhem como se fossem pesquisadores, investigando os problemas matemáticos propostos pelo professor, construindo soluções ao invés de esperarem um modelo a ser seguido.

Nesta perspectiva, esta pesquisa justificou o seu estudo pelo fato das potencialidades existentes nas atividades investigativas e da utilização da tecnologia no ensino de Matemática. De fato, 
muitos dos alunos consideram a disciplina difícil de entender e não conseguem perceber a sua utilização no dia a dia. Assim, devido à importância desta disciplina para os estudantes, foi analisada a eficácia da atividade investigativa aliada à utilização de Mídias Tecnológicas, com o uso do software Geogebra no ensino de funções, tornando o software um meio que facilita a visualização gráfica, podendo comparar com a parte algébrica e assim favorecendo o aprendizado do aluno.

\section{Funções quadráticas: um problema muito antigo}

Segundo Lima (2006, p. 119), o estudo das funções quadráticas tem sua origem na resolução da equação do segundo grau; problemas que recaem na equação do segundo grau estão entre os mais antigos na História da Matemática. De acordo com Lima (2006, p. 119), em textos cuneiformes escritos pelos babilônios há quase quatro mil anos, encontra-se a questão de achar dois números conhecendo sua soma $s$ e seu produto $p$.

Em termos geométricos, este problema também é conhecido como a determinação dos lados de um retângulo, em que o semiperímetro é o valor de s e a área o valor de $p$, ou seja, os valores procurados são as raízes da equação do segundo grau $x^{2}-s x+p=0$.

Se um dos números é $x$, o outro é $(s-x)$ e seu produto é $p=x(s-x)=s x-x^{2}$, portanto $x^{2}-s x+p=0$.

Observando que se $\alpha$ é uma raiz desta equação, isto é, $\alpha^{2}-s \alpha+p=0$, então $\beta=s-\alpha$ também é raiz, visto que $\beta^{2}-s \beta+p=(s-\alpha)^{2}-s(s-\alpha)+p=s^{2}-2 s \alpha+\alpha^{2}-s^{2}+s \alpha+p=$ $\alpha^{2}-s \alpha+p=0$.

Encontrar as raízes da equação $x^{2}-s x+p=0$, por meio dos seus coeficientes, surgiu no final do século XVI. De acordo com Lima (2006), até o fim do século XVI, não se usava uma fórmula para os valores das raízes, simplesmente porque não se representavam por letras os coeficientes de uma equação. Lima (2006) destaca que isto começou a ser feito a partir de François Viéte, matemático Francês que viveu de 1540 a 1603.

Antes da notação dos coeficientes, o que se tinha era uma receita que ensinava como proceder em exemplos concretos (com os coeficientes numéricos), ou seja, a regra para encontrar dois números cuja a soma e cujo o produto são dados, era assim enunciada pelos babilônios: Eleve ao quadrado a metade da soma, subtraia o produto e extraia a raiz quadrada da diferença. Some ao resultado a metade da soma. Isso dará o maior dos números procurados. Subtraia-o da soma para obter o outro número (LIMA, 2006).

Em notação atual, esta regra fornece as raízes $x=\frac{s}{2}+\sqrt{\left(\frac{s}{2}\right)^{2}-p}$ e $x=\frac{s}{2}-\sqrt{\left(\frac{s}{2}\right)^{2}-p}$ para a equação $x^{2}-s x+p=0$.

Segundo Lima (2006), os textos cuneiformes não deixam registrado o argumento que os levou a esta conclusão, mas há indícios de que pode ter sido algo assim: 
Sejam $\alpha$ e $\beta$ os números procurados, tais que $\alpha \leq \beta$. Esses números $\alpha$ e $\beta$ são equidistantes da média aritmética $\frac{s}{2}=\frac{\alpha+\beta}{2}$. Conhecendo a diferença $d=\beta-\frac{s}{2}=\frac{s}{2}-\alpha$, tem-se os dois núme$\operatorname{ros} \alpha=\frac{s}{2}-d$ e $\beta=\frac{s}{2}+d$. Mas $d$ é fácil de encontrar, visto que: $p=\alpha \beta=\left(\frac{s}{2}-d\right)\left(\frac{s}{2}+d\right)=\left(\frac{s}{2}\right)^{2}-$ $d^{2}$. Logo, $d^{2}=\left(\frac{s}{2}\right)^{2}-p$ e $d=\sqrt{\left(\frac{s}{2}\right)^{2}-p}$. Portanto, $\alpha=\frac{s}{2}-d=\frac{s}{2}-\sqrt{\left(\frac{s}{2}\right)^{2}-p}$ e $\beta=\frac{s}{2}+d=\frac{s}{2}+$ $\sqrt{\left(\frac{s}{2}\right)^{2}-p}$

$\mathrm{Na}$ época, $s$ e $p$ do problema eram sempre números positivos. Os babilônios nunca tiveram a preocupação com eventuais casos em que $\left(\frac{s}{2}\right)^{2}<p$, conforme o problema de encontrar dois números cuja soma e cujo o produto resultam em 2 (LIMA, 2006, p. 121).

Um dos grandes desafios, ainda sem solução até o presente momento, é encontrar um método que verifique quadrados perfeitos em uma função quadrática $f(x)=a x^{2}+b x+c$, em que o coeficiente $a$ é um quadrado perfeito; mais especificamente a função $f(m)=(m-n-1)^{2}-4 n$, em que $n=p . q$ e os valores de $p$ e $q$ são números primos; a descoberta desse método que encontre quadrados perfeitos em uma função quadrática terá certas consequências na aplicação da Criptografia RSA (MOLINARI, 2016).

\section{Mídias tecnológicas e o software Geogebra}

De acordo com Moran (2007), as novas tecnologias na escola estão sendo implantadas gradativamente e o professor deve ter um papel indispensável nesse processo de renovação. Essas tecnologias precisam ser compreendidas como ferramentas que auxiliam o trabalho do professor, levando em conta que o aluno tem disponível um mundo de informações na internet e a maioria manuseia estas ferramentas (celulares, tablets, iphone etc.) com desenvoltura e rapidez.

Uma forma de abordagem que trabalha diretamente com a interação do aluno com o computador é a proposta construtivista, sob a qual o professor toma o papel de mediador entre o aluno e o computador no processo de ensino e aprendizagem. Nessa proposta, o desenvolvimento cognitivo é um processo ativo de construção e de reconstrução das estruturas mentais em que o conhecimento não pode ser simplesmente transmitido pelo professor para o aluno (MALTEMPI, 2005).

Segundo Valente (1996), os softwares educativos são softwares pensados, programados e implementados para objetivos educacionais, fora e dentro da escola. Seu principal propósito é o ensino ou o auto aprendizado e têm como objetivo principal contribuir para que o estudante obtenha novos conhecimentos. Podem ser classificados tutoriais, jogos educacionais, exercício e prática de simulação, de geometria dinâmica, entre outros. Entre esses softwares destaca-se o Geogebra, que facilita a interpretação gráfica de funções. 
O software Geogebra possibilita que o aluno construa gráficos e objetos e explore ao mesmo tempo suas características geométricas e algébricas, bem como as particularidades e generalizações presentes nas construções. Ao fazer este tipo de abordagem, insere-se o aluno em um ambiente de aprendizado em que ele pode interagir com os gráficos das funções de modo que lhe seja facilitada a abstração dos mesmos. Os softwares de geometria dinâmica têm um diferencial, de acordo com Inforsato (2009, p. 01):

[...] possuem recursos que possibilitam a transformação contínua, em tempo real, ocasionada pelo arrastar do mouse. Estes recursos permitem explorar propriedades geométricas de forma muito mais eficiente do que quando se utilizam somente os instrumentos convencionais tais como régua e compasso.

De acordo com Valente (1997), a implantação destes ambientes virtuais de ensino está ligada à melhoria da compreensão dos conteúdos pelos alunos, possibilitando a passagem do saberfazer para o compreender. Logo, os softwares educacionais como o Geogebra facilitam a visualização e aumentam as possibilidades de experimentação e investigação matemática.

\section{Metodologia}

Foram abordados em sala de aula os conteúdos anteriores necessários à aprendizagem de funções quadráticas, tais como as equações polinomiais do primeiro e segundo graus e o plano cartesiano. Com relação à revisão, foi dada maior ênfase sobre a principal diferença entre equação e função.

Realizou-se uma atividade em grupo, sendo anotados no quadro alguns pontos do plano cartesiano, em que utilizou-se de uma fita crepe para projetar o plano cartesiano no chão e assim foi solicitado a cada aluno que encontrasse um ponto distinto em seu respectivo quadrante, ou no eixo da abcissa ou no eixo da ordenada. Percebeu-se que a maioria ficou motivada ao revisar o conteúdo de uma maneira alternativa e também notou-se que a maior dificuldade encontrada foi na localização dos pontos situados nos eixos ortogonais.

Em seguida, foi abordado o conteúdo de funções quadráticas e os seus respectivos gráficos. Foram necessárias 5 (cinco) aulas de 50 (cinquenta) minutos para a abordagem do conteúdo e a realização das atividades com o uso do software Geogebra, organizado da maneira como segue.

\subsection{Aula introdutória de funções quadráticas}

Foram apresentadas algumas informações sobre certas modalidades olímpicas, como o arremesso de peso e o lançamento de dardo e comentou-se sobre a utilização da função quadrática na tentativa de explicar a trajetória do lançamento de projéteis.

Com o intuito de despertar a curiosidade dos alunos foram mencionados outros acontecimentos que também podem ser explicados de acordo com uma função quadrática. Foi pedido que eles imaginassem a trajetória do arremesso de peso e fizessem um desenho no caderno. Todos os desenhos ficaram semelhantes à representação de uma parábola, então foi apresentada, em slides, 
essa mesma trajetória e também algumas imagens referentes às modalidades olímpicas distintas, como a trajetória de um arremesso de peso, uma bola de golfe após uma tacada e uma bola de futebol, entre outras situações, conforme a Figura 1.

Figura 1 - Trajetória de um arremesso de peso; trajetória de uma bola de golfe; trajetória de uma bola de futebol.

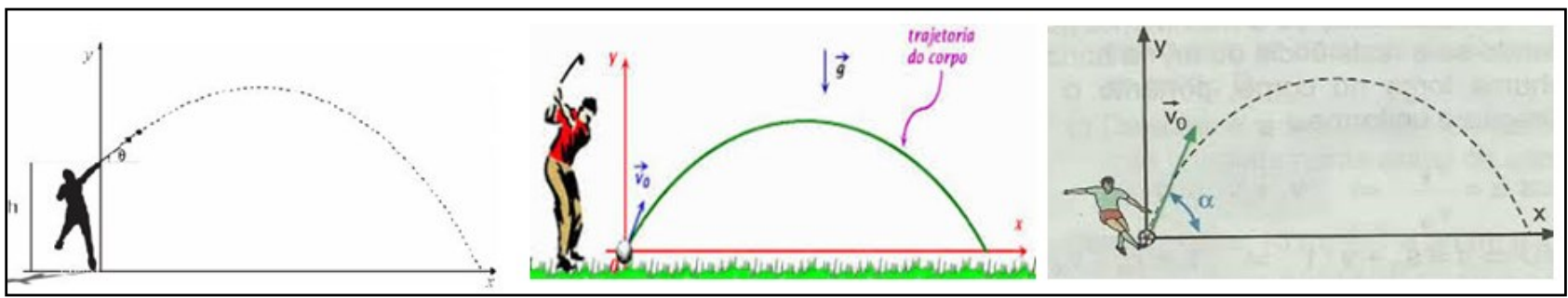

Fonte: Projeto "Somos Físicos" (http://www.vanialima.blog.br/search?q=par\%C3\%A1bola).

Na sequência, foi explicitado que a trajetória formada por essas situações e outras presentes em modalidades olímpicas, é modelada a partir de uma função quadrática.

Foi então apresentada a forma canônica da função quadrática, em que a função $f: \Re \rightarrow \Re$ tal que $x \in \mathfrak{R}$ e $f(x)=a x^{2}+b x+c$, em que $a, b, c$ são números reais com $a \neq 0$.

As funções quadráticas em que $b \neq 0$ e $c \neq 0$ são definidas como funções completas, e quando $b=0$ ou $c=0$ são definidas como funções incompletas. Em seguida, foram apresentados alguns exemplos numéricos de representações de funções quadráticas e um exercício com questões objetivas para os alunos identificarem quais dos exemplos eram funções quadráticas e também determinarem os valores dos coeficientes, indicando se era uma função completa ou incompleta. Foram relacionado algumas funções com algumas áreas, como por exemplo, escrever uma fórmula que expressasse uma área $A$ em função de uma medida $x$, de um terreno retangular, sabendo que seu comprimento excede em 9 metros a largura, como mostra a Figura 2.

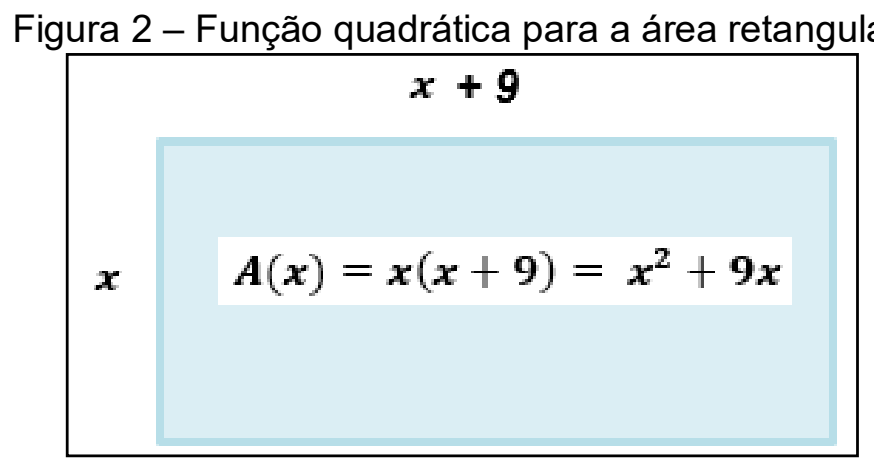

Fonte: Elaboração dos autores.

Desta maneira, na aula introdutória, foi possível contextualizar algumas das aplicações existentes que abordam o assunto de funções quadráticas. 


\subsection{Aplicação de pontos no domínio}

Foram propostos exercícios de aplicação de pontos para determinarem o valor da função, antes foi resolvido com os alunos um exemplo no quadro, da seguinte forma: Determinar os valores da função $f(x)=x^{2}+2 x-1$ para $f(3), f(0)$ e $f(-5)$.

Em seguida, foram escritos no quadro outros exercícios similares ao do exemplo, para os alunos resolverem; eles copiavam e, enquanto resolviam, tiravam suas dúvidas. Neste momento, não houve nenhuma dificuldade sobre como realizar a atividade e os erros eram somente em relação aos cálculos.

\subsection{Gráfico de uma função quadrática}

Foi comentado novamente, com os alunos, sobre as imagens referentes às modalidades olímpicas, mostrando gráficos de funções quadráticas, para que eles observassem a semelhança, antes de realmente desenharem eles mesmos os gráficos. Primeiramente, foram dadas algumas funções, foi pedido para que eles encontrassem os valores das funções para valores inteiros no domínio $x=[-2,2]$, como já haviam feito anteriormente e depois foi mostrado a eles como mais valores podem ser substituídos na função. Foi feito um pequeno quadro, em que tivessem respectivamente os valores de $x$ e o seu correspondente $f(x)$, formando assim um par ordenado, em que $f(x)=y$. Foi construído no software Geogebra, por meio do menu de entrada e concomitantemente no caderno (quadriculado) com auxílio da régua, o desenho dos eixos do plano cartesiano, para determinar os pares ordenados, em que ligando esses pontos, estar-se-ia construindo o gráfico da função, formando então o desenho de uma parábola, conforme a Figura 3.

Figura 3 - Pontos da função aplicados no eixo (esquerda) e parábola correspondente à função (direita).

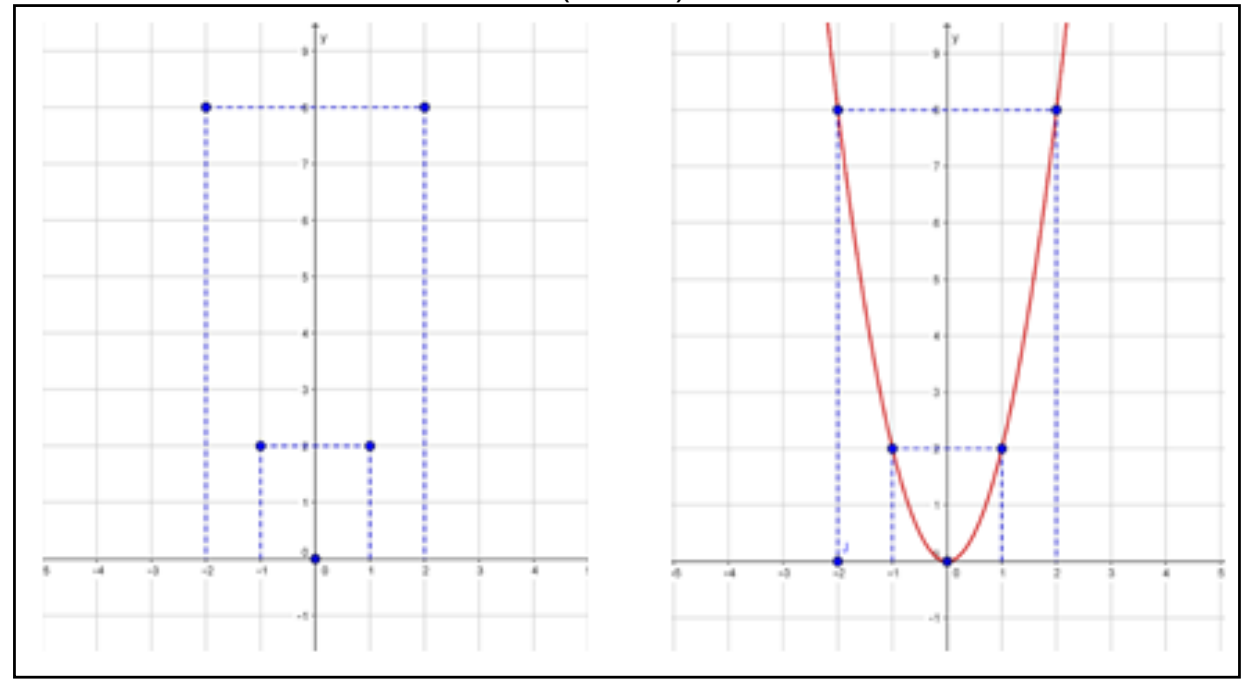

Fonte: Elaboração dos autores.

Em seguida, foi explicado que o gráfico de uma função quadrática é uma curva chamada parábola, como já haviam observado anteriormente e que esta parábola possui um eixo de simetria, 
no caso da função acima é o eixo das ordenadas (eixo $y$ ). A partir de exemplos de gráficos de funções apresentados em slides, foi mostrado aos alunos que o ponto em que a parábola intercepta o eixo das ordenadas é quando o $x$ é igual a 0 , ou seja, para obter a interseção da parábola com o eixo $y$, basta encontrar o valor da $f(x)$ para $x=0$. A partir dos exemplos, foi feita a observação com os alunos sobre a concavidade da parábola, em que para $a<0$, a concavidade é voltada para baixo e se $a>0$ a concavidade é voltada para cima e mostrando as simulações no software Geogebra, de acordo com as Figuras 4 e 5.

Figura 4 - Gráfico da função $f(x)=-x^{2}+4 x+1, a=-1$, ou seja, $a<0$ (negativo).

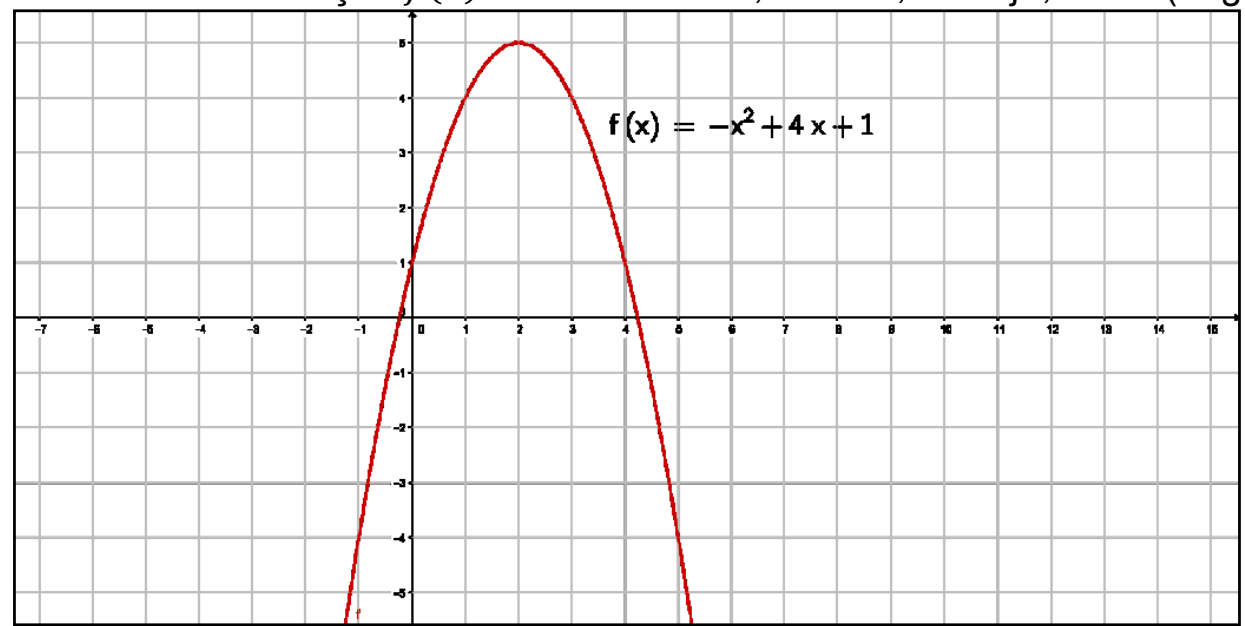

Fonte: Elaboração dos autores.

Figura 5 - Gráfico da função $f(x)=3 x^{2}+2 x-1, a=3$, ou seja, $a>0$ (positivo).

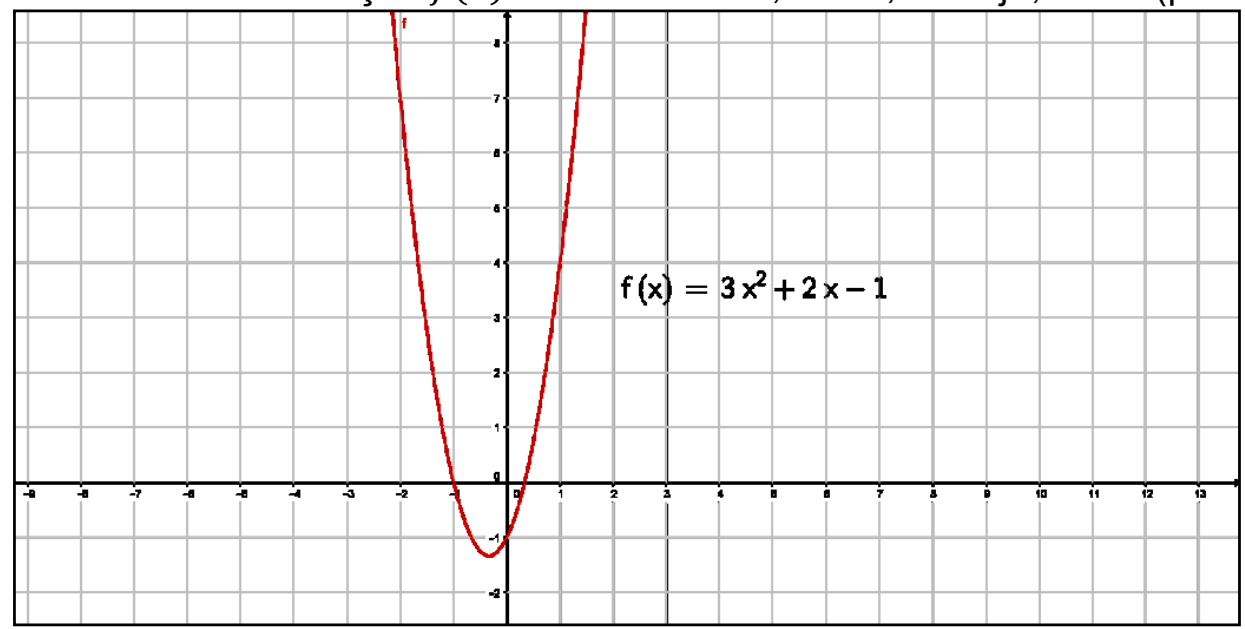

Fonte: Elaboração dos autores.

Após a contextualização do coeficiente $a<0$ e $a>0$, foi realizado um questionamento com os alunos, de como seria então o gráfico da função quadrática para $a=0$ ? Poucos alunos responderam que não seria uma função quadrática. Então foi mostrado um exemplo para eles, em que $a=0$ e $b \neq 0$ representa uma função afim como as que haviam visto no conteúdo anterior. 


\subsection{Zeros de uma função quadrática}

Assim, como os alunos já haviam visto em função afim, para determinar os zeros de uma função quadrática $f(x)=a x^{2}+b x+c$,foi proposto em forma de desafio encontrarem os valores de $x$ que fizessem o valor da função zerar, ou seja para quais valores $f(x)=0$.

No início, tiveram um pouco de dificuldade em interpretar o que deviam fazer, então foi resolvido com eles um exemplo e mostrado que, ao substituir o $x$ por um (1), a função teria valor zero (0) e que isso também aconteceria ao substituirmos o valor menos dois (-2) e que poderiam ir substituindo, nas outras funções, alguns valores para tentar encontrar quais fariam a função zerar.

Depois de todos encontrarem pelo menos um valor em alguma das funções, foi explicado que existem alguns métodos que podem ser utilizados para encontrar de um modo mais rápido esses valores, chamados de zeros das funções. Um desses métodos é a fórmula resolutiva da equação do segundo grau (Fórmula de Bhaskara), em que verificaram o mesmo resultado de quando substituíram os pontos e, em seguida, foram propostas mais algumas funções para determinarem as raízes (zeros das funções). Enquanto eles resolviam, perguntavam e tiravam dúvidas e, assim que todos acabaram de resolver, foram feitas as correções dos exercícios no quadro.

\subsection{Resolução: estudo do ponto de máximo ou mínimo}

Com o auxílio do Geogebra, foram estudadas algumas imagens de gráficos de funções quadráticas (exemplos nas Figuras 6 e 7) e foi comentado sobre o ponto de máximo e de mínimo, quais eram suas localizações a partir dos gráficos e de suas respectivas funções. Foi explicado que, se a função tiver a concavidade voltada para cima $(a>0)$, teremos um ponto de mínimo, conforme Figura 6.

Figura 6 - Ponto de mínimo da função.

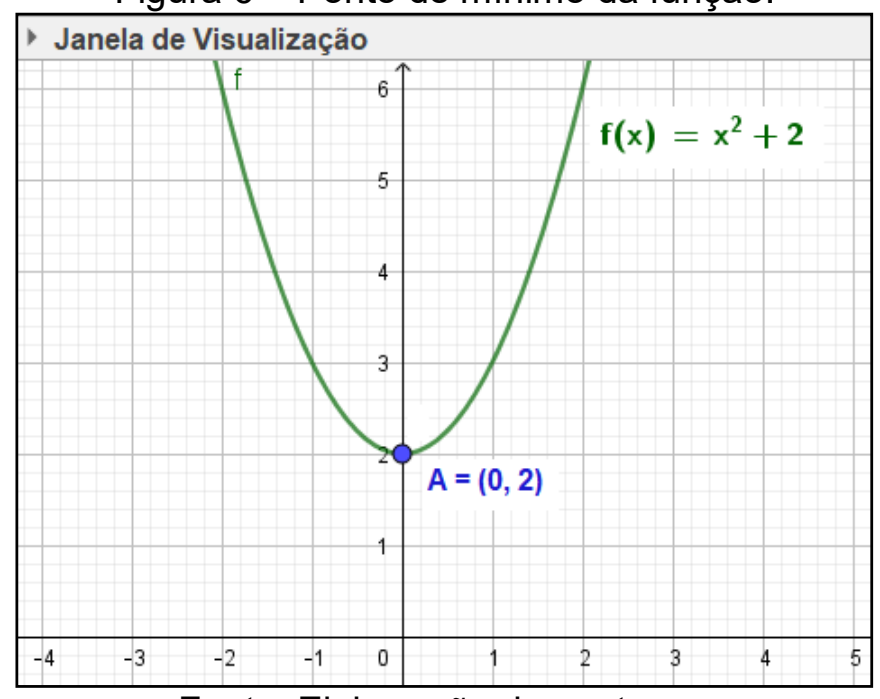

Fonte: Elaboração dos autores.

Se o gráfico da função tiver concavidade voltada para baixo $(a<0)$, tem-se um ponto de máximo e como encontrá-los a partir das coordenadas do vértice: $x_{v}=-\frac{b}{2 a}$ e $y_{v}=-\frac{\Delta}{4 a}$. 
Figura 7 - Ponto de máximo da função.

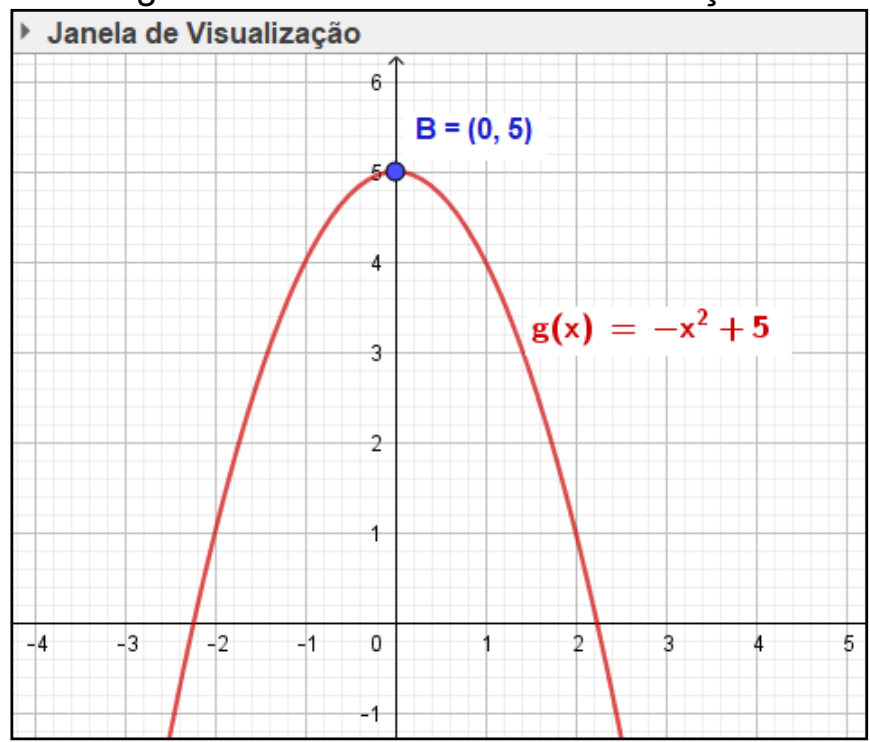

Fonte: Elaboração dos autores.

Em seguida, apenas no caderno, foram utilizados os exemplos anteriores das funções e pedido somente que encontrassem os valores do ponto de mínimo ou de máximo de cada uma das funções e também identificando se corresponde a uma função com concavidade voltada para cima ou concavidade voltada para baixo.

\subsection{Construção gráfica}

Nesta parte, os alunos foram instruídos a observar o que já haviam feito ou descoberto, como os zeros da função e o ponto de máximo ou de mínimo.

Na sequência, foi entregue uma atividade contendo diferentes funções, para que eles desenhassem os gráficos delas em seus cadernos. A maioria começou substituindo os valores no domínio, encontrando assim os pares ordenados e desenhando o gráfico da função.

Em seguida, foi desenvolvido junto com eles um exemplo de como poderiam desenhar o gráfico da maneira mais simples, sem precisarem encontrar muitos pontos, analisando apenas a função, na concavidade da parábola $(a>0)$ ou $(a<0)$, encontrando o ponto de máximo ou de mínimo, encontrando as raízes $(f(x)=0)$, e também se necessário encontrar $f(0)$ para determinar onde a função intercepta o eixo das ordenadas e assim bastaria marcarem no plano cartesiano esses pontos e desenharem o gráfico, ou seja, mostrando a eles que, a partir disso, poderiam analisar os gráficos e suas respectivas funções.

\subsection{Utilização do software Geogebra para a construção dos gráficos e análises}

Com relação ao software Geogebra, versão 5.0, disponível no laboratório de informática da escola em que foi aplicada a referida pesquisa, foi feita uma aula expositiva no projetor, mostrando seus principais recursos e como utilizá-los na construção de gráficos. 
Posteriormente, foram propostas algumas funções para desenharem os gráficos, mas agora com a utilização do Geogebra; os alunos foram em trios para o laboratório de informática, para o conhecimento das ferramentas e a exploração do software.

Depois de todos terem um conhecimento prévio de como construírem os gráficos, foi deixado livre para os alunos utilizarem o software e desenvolverem a atividade proposta. Quando todos fizeram a construção de pelo menos um gráfico, digitando a função quadrática no campo de entrada do software, foi abordada a questão do comportamento da função, da mesma forma de quando haviam desenhado somente no caderno.

Próximo ao término da aula, realizou-se um momento de contextualização, e também foi verificado se havia dúvidas sobre a atividade realizada anteriormente. Na sequência, foi entregue um questionário contendo sete questões, as quais foram respondidas até o término da aula, com perguntas referentes ao conteúdo abordado e a utilização do software Geogebra.

\section{Resultados e discussão}

A seguir, tem-se algumas respostas dos alunos, nas Figuras 8 e 9, quanto à aplicação da proposta de pesquisa, relacionada à utilização do software Geogebra, o qual proporcionou uma experiência diferenciada relacionada ao conteúdo visto em sala de aula.

Figura 8 - Resposta do Aluno 1.

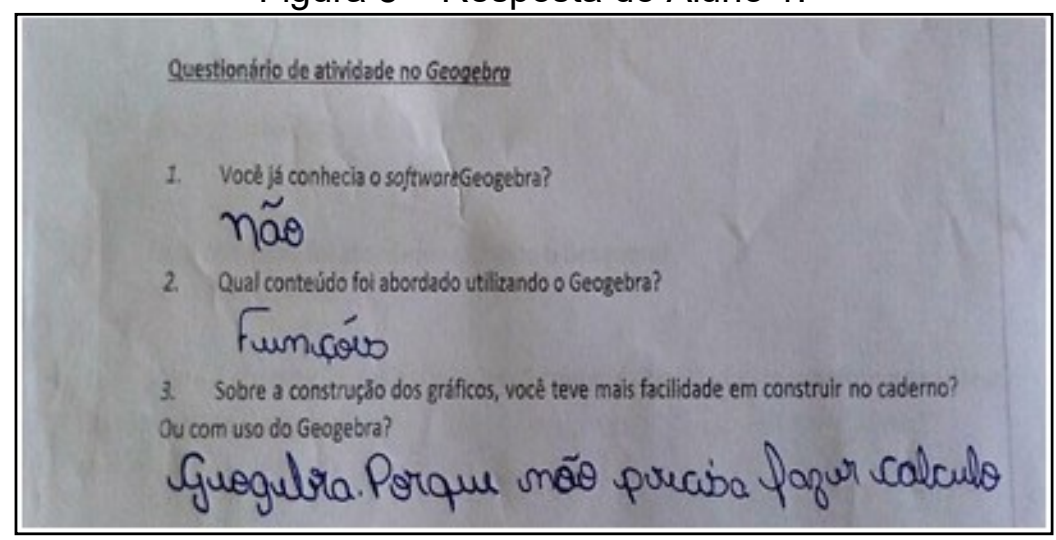

Fonte: Dados da pesquisa.

Figura 9 - Resposta do Aluno 2.

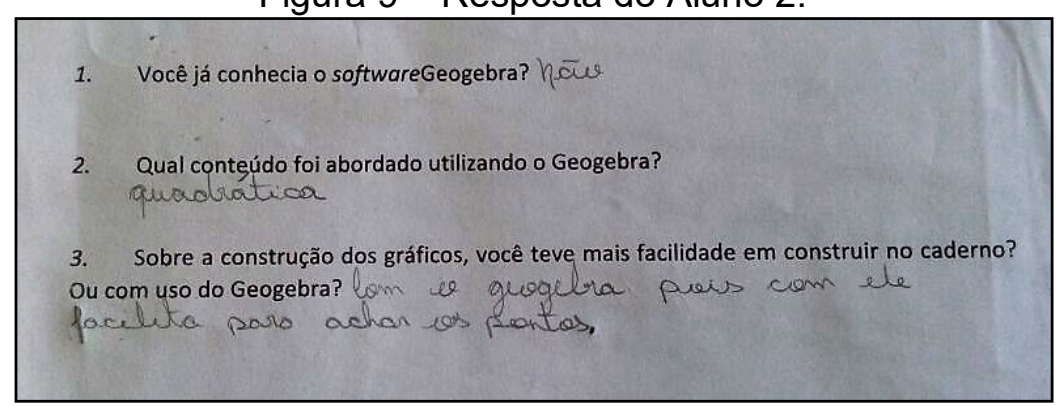

Fonte: Dados da pesquisa. 
Observou-se que houve uma melhor fixação dos conceitos diante da utilização do software Geogebra, que reúne elementos algébricos relacionados à geometria, facilitando assim a visualização e a interpretação, como por exemplo a relação do sinal do coeficiente $a$ da função, em que os alunos comentaram que, com apenas uma mudança de sinal, observavam a mudança da concavidade da parábola.

Verificaram também o que acontecia com as raízes da função ao alterar os valores dos coeficientes, construindo assim os gráficos de funções que nem estavam na atividade proposta, ou seja, eles estavam investigando por si próprios o que mais poderiam fazer com o uso do Geogebra. As Figuras 10, 11 e 12 apresentam algumas respostas dos alunos.

Figura 10 - Resposta do Aluno 3.

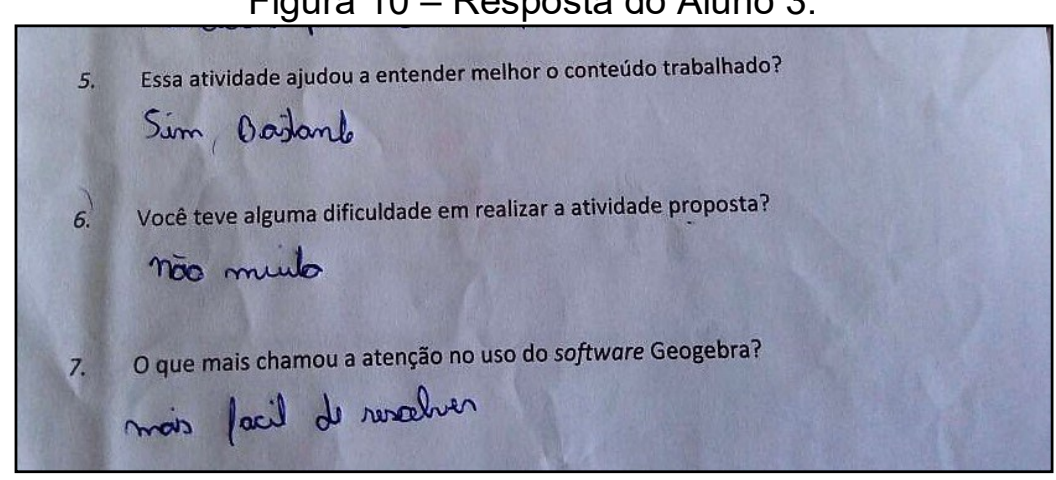

Fonte: Dados da pesquisa.

Figura 11 - Resposta do Aluno 4.

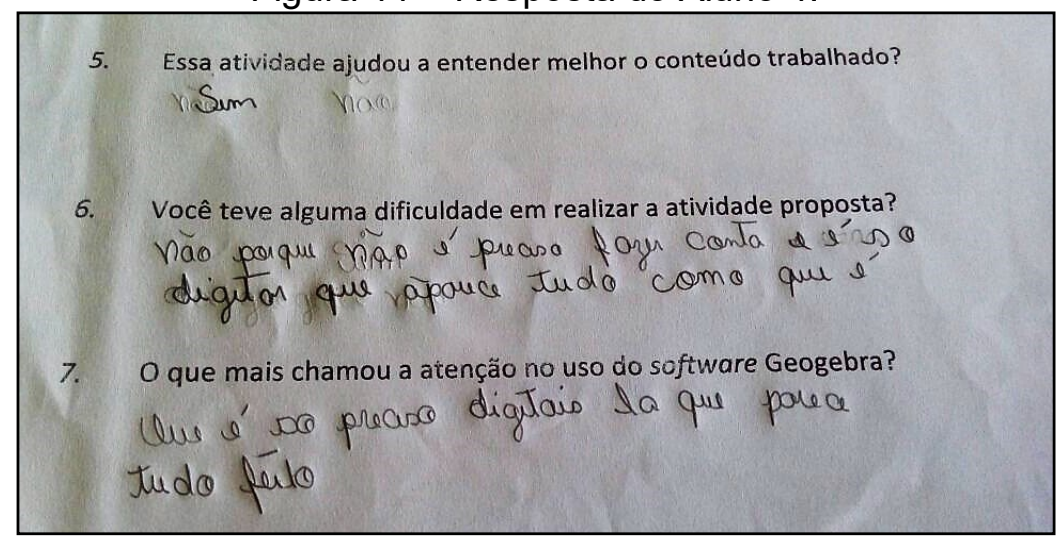

Fonte: Dados da pesquisa.

Figura 12 - Resposta do Aluno 5.

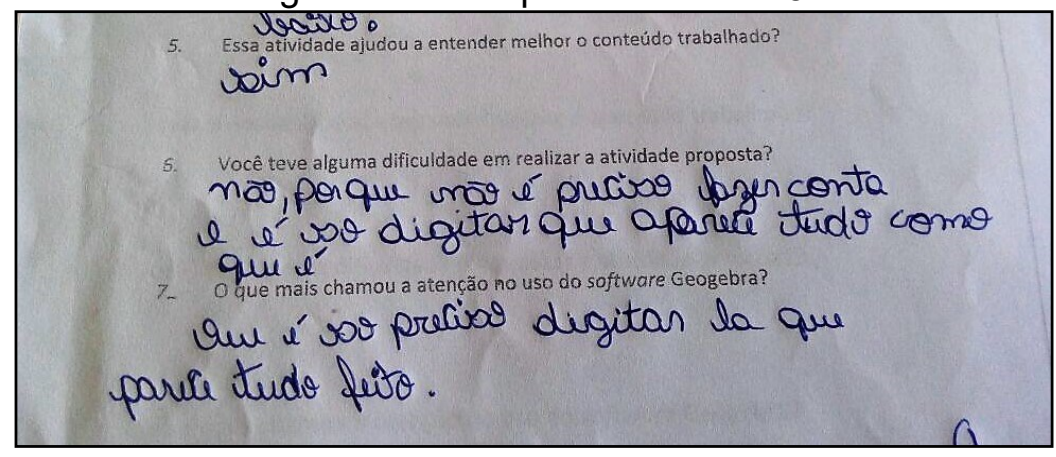

Fonte: Dados da pesquisa. 
Após a análise dos questionários, verificou-se que o ensino de funções quadráticas com a utilização do software Geogebra despertou o interesse da maioria dos alunos, por se tratar de uma abordagem diferente da tradicional. A facilidade que o software traz para a análise gráfica de cada função foi muito proveitosa, em que os mesmos questionavam se podiam analisar casos específicos de funções do segundo grau, desenvolvendo também, como a teoria de Piaget, o surgimento de hipóteses até chegarem na construção do conhecimento. Em seu trabalho, Fernandes et al. (2017) também obtiveram resultados favoráveis quanto ao uso dos recursos das mídias tecnológicas. Rehfeldt et al. (2018), por meio da modelagem matemática, contextualizaram como mais eficaz a sua abordagem no estudo da conta de água.

\section{Considerações finais}

A investigação do uso de mídias tecnológicas no ensino de funções quadráticas foi bem proveitosa, pois proporcionou ao aluno o contato com novas linguagens e como a tecnologia faz parte da realidade da maioria deles desde pequeno, tornou o ensino mais próximo da realidade e também facilitou o modo de trabalhar o conteúdo, que com apenas o quadro e giz não ficaria tão claro.

Nos anos anteriores a esta pesquisa, utilizou-se apenas o quadro e o giz para o ensino da função polinomial do segundo grau e percebeu-se que, com a utilização do software Geogebra, houve uma melhora em termos de aprendizado e fixação do conteúdo, mediante a aplicação da mesma prova dos anos anteriores. A maioria os alunos conseguiram construir os gráficos, calcularam as raízes e encontraram o ponto de mínimo ou de máximo para cada função proposta.

Portanto, a referente pesquisa foi motivacional, no sentido de despertar nos alunos a parte investigativa dos conceitos na Função Quadrática, assim como a manipulação do software em questão, que possibilitou desafios e descobertas.

\section{Referências}

FERNANDES, V. M. J.; MARZAGÃO, A. V.; SANTOS, M. E. K. L. Professor tutor e as técnicas utilizadas para avaliação do aluno na modalidade EAD. Revista REnCiMa, v. 8, n. 5, p. 99-113, 2017.

INFORSATO A. P. Atividades Investigativas com Software de Geometria Dinâmica. In: XXI Congresso de iniciação científica da UNESP. São José do Rio preto, UNESP 2009.

LIMA, E. L. A Matemática do Ensino Médio. v. 1. 9. ed. Rio de Janeiro: SBM, 2006. Coleção do Professor de Matemática.

MALTEMPI, M. V. Construcionismo: Um pano de fundo para pesquisas em informática aplicada à educação matemática. v. 1. 1. ed. São Paulo, SP: Cortez, 2005, p. 264-282.

MOLINARI, J. R. A. Números Primos e a Criptografia RSA. Ponta Grossa, 2016. 56 f. Dissertação (Mestrado em Matemática) - Universidade Estadual de Ponta Grossa, Ponta Grossa, 2016. 
MORAN, J. M. Desafios na comunicação pessoal. 3. ed. São Paulo: Paulinas, 2007, p. 162-166. PONTE, J. P. M.; BROCARDO, J.; OLIVEIRA, H. Investigações matemáticas na sala de aula. Belo Horizonte: Autêntica, 2006.

REHFELDT, M. J. H.; NEIDE, I. G.; BÖCKEL, W. J.; BROILO, A. P.; PISCHING, I; HEINEN, C. A.; KÖNIG, R. I. Modelagem matemática no Ensino Médio: uma possibilidade de aprendizagem a partir de contas de água. Revista REnCiMA, v. 9, n. 1, p. 103-121, 2018.

SEED. Secretaria de Estado da Educação do Paraná. Diretrizes curriculares de Matemática para a educação básica. Curitiba, 2008.

VALENTE, J. A. O uso inteligente do computador na educação. Revista Pátio, ano I, n. 1, maiojul., 1997.

VALENTE, J. A. A informática na educação: conformar ou transformar a escola. Perspectiva. Florianópolis, UFSC/CED, NUP, n. 24, p. 41-49, 1996. 